Research Article

\title{
Predictive value of subendometrial - endometrial blood flow assessment by transvaginal 3D power doppler on the day of HCG on clinical outcome of IVF cycles
}

\author{
Manisha Choudhary ${ }^{1}$, Jai Chowdhary ${ }^{2}$, Mohan Lal Swarankar ${ }^{1}$, Shiv Lal Bharadwaj ${ }^{3}$
}

\begin{abstract}
${ }^{1}$ Department of Obstetrics \& Gynaecology, ${ }^{2}$ Department of Radio-Diagnosis, ${ }^{3}$ Department of Preventive and Social Medicine, Mahatma Gandhi Medical College \& Hospital, Jaipur, Rajasthan, India
\end{abstract}

Received: 24 August 2015

Revised: 20 September 2015

Accepted: 05 October 2015

\section{*Correspondence:}

Dr. Manisha Choudhary,

E-mail: drmanishachowdhary@gmail.com

Copyright: (c) the author(s), publisher and licensee Medip Academy. This is an open-access article distributed under the terms of the Creative Commons Attribution Non-Commercial License, which permits unrestricted non-commercial use, distribution, and reproduction in any medium, provided the original work is properly cited.

\section{ABSTRACT}

Background: The objective of the study was to evaluate the role of subendometrial-endometrial blood flow assessment by 3D Tran-vaginal Power Doppler in predicting pregnancy outcome in IVF-ET cycles. The study was a prospective, non-randomized clinical study.

Methods: A total of 107 infertile women undergoing their first IVF-ET cycle with good response were taken for study (From March 2014 to Nov 2014 at Jaipur Fertility Centre, ART unit of Mahatma Gandhi University of Medical Sciences \& Technology). Women with Tubal factor, Male factor and unexplained infertility were included in the study. Those with past h/o Genital Koch's and hypo menorrhea were excluded. Assessment of subendometrialendometrial blood flow was done on the day of HCG with endometrial thickness $\geq 6.5 \mathrm{~mm}$ by Tran-vaginal 3D- Power Doppler.

Results: There was no significant difference in mean age, duration of infertility, BMI, cause of infertility, stimulation protocol, serological hormone levels, number of mature oocytes, number of good quality embryos and mean endometrial thickness on the day of HCG. According to Doppler study (3D-Power Doppler), women with blood flow to zones 1,2 and 3 were categorized in to groups $A(n=15), B(n=36)$ and $C(n=56)$. Overall pregnancy rate was $32.71 \%$. The clinical pregnancy rate was significantly higher in Group C in comparison of Group B and A $(42.85 \%$ vs. $27.77 \%$ and $6.66 \%)$. Similarly implantation rate was also higher in group C (23.20\% vs. $11.22 \%$ and $2.38 \%)$.

Conclusions: The presence of good subendometrial-endometrial vascularity significantly improves pregnancy outcome in IVF-ET cycles in our study.

Keywords: HCG, 3D-Power Doppler, Subendometrial-endometrial blood flow

\section{INTRODUCTION}

The role of ART in infertility is increasing rapidly with time since the birth of first baby in 1978. Despite numerous developments in Assisted Reproduction, the clinical pregnancy rate (CPR) in IVF is still low. It has been estimated that up to $85 \%$ of the embryos replaced into the uterine cavity fail to implant. ${ }^{1}$ The cause of this low CPR may reside in the technique of embryo transfer, the endometrial receptivity or the capacity of the embryo to properly invade the endometrium. Successful implantation depends on a close dialogue between the blastocyst and the receptive endometrium during implantation window which is the window of time when the uterine environment is conducive to blastocyst acceptance and subsequent implantation.

Past studies related to endometrial receptivity were mainly focused on endometrial biopsy and its histopathological examination as endometrial dating by Noyes 
criteria, ${ }^{2}$ endometrial cytokines in uterine flushing, ${ }^{3}$ investigations of the receptors for estrogen and progesterone etc. These invasive methods were not accepted by patients because of risk of infection, doubt of subsequent abortion and inability to use same cycle for conception.

In contrast to previous methods, Trans-vaginal ultrasonography is a non-invasive, efficient, safe and cost effective modality for monitoring functional changes during spontaneous and induced cycles. ${ }^{4,5}$ Ultrasound parameters of endometrial receptivity includes endometrial thickness, endometrial pattern, endometrial volume and Doppler studies of uterine vessels and the endometrium. Power and colour Doppler assessment is applied for the study of different variables of uterine and endometrial-subendometrial perfusion that are also used as receptivity markers. ${ }^{6}$ Power Doppler is more reliable because signal amplitude mapping detects lower blood flow velocities and is unaffected by the angle of insonation. A good blood supply towards the endometrium is usually considered to be an essential requirement for implantation. Doppler study of uterine arteries does not reflect the actual blood flow to the endometrium. The endometrial vascularity has a useful predictive value on the implantation rate in IVF cycles irrespective of morphological appearance of the endometrium. The aim of our study is to evaluate the role of endometrial and subendometrial vascularity by TVS 3D-Power Doppler in predicting pregnancy outcome in IVF cycles.

\section{METHODS}

This prospective clinical study was done at the ART unit of Mahatma Gandhi University of Medical Sciences and Technology. 107 patients undergoing 1st cycle of IVFET/ICSI were included in the study group (from March 2014 to November 2014). All patients included were of age group 21 to 38 Years with primary / secondary infertility of various etiologies like tubal, ovulation failure and male factor. Cases with history of genital Koch's, hypo menorrhea, fibroids, hydrosalpinx and grade III or IV endometriosis were excluded from the study.

All patients received a long protocol of pituitary down regulation with $\mathrm{GnRh}$ agonist (Inj. Lupride $0.5 \mathrm{mg}$ S.C. daily, Sun Pharma) from the mid luteal phase of the cycle preceding the treatment cycle followed by stimulation using recombinant FSH (Inj. Gonal-F, Merck Serono S.A., Switzerland) or urinary HMG (Inj. Menogon, Ferring, Germany) in doses according to age, BMI and ovarian reserve of patients. HCG 10,000 I.U. (Inj. Sifasi, Serum Institute) was given for final trigger. Ovum retrieval was done 36 hours after HCG administration.

On the day of HCG ultrasound measurement of endometrial thickness, pattern, blood flow of the subendometrial radial arteries and endometrial spiral arteries were performed by trans vaginal $6.5 \mathrm{MHz}$ Power Doppler system.

Double layer thickness of the endometrium was measured (maximum distance between each myometrialendometrial interface through the longitudinal axis of the uterus). Endometrial pattern was classified as types A (hyperechoic), B (isoechoic) and C (triple line).

The zones of vascular penetration have been defined as zone I i.e. the subendometrial zone, zone 2 is the outer hyperechogenic zone and zone 3 is the inner hypoechogenic zone.

Patients had two or three embryos replaced into the uterine cavity on day 3 after oocyte retrieval. Luteal phase support was given by vaginal natural micronised progesterone suppositories (Cap Gestone 200mg thrice daily, Ferring). On day 15 after embryo transfer, serum HCG was done for IVF outcome. $\beta-H C G \geq 50 \mathrm{mIu} / \mathrm{ml}$ was considered as positive. Trans vaginal ultrasound was done on day 30 after embryo transfer. Clinical pregnancy was defined as presence of one or more gestational sacs or the histological confirmation of gestational products in case of miscarriage. When no gestational sac could be seen with positive $\beta$-HCG by 6 weeks, it was defined as a biochemical pregnancy. Poor pregnancy outcome includes the patients with biochemical pregnancy and miscarriage.

\section{Statistical analysis}

In the present study, the data was collected on Microsoft Excel sheet. Independent two-tailed t-test was used to evaluate the significance of continuous variables like age, BMI etc., $\mathrm{P}<0.05$ was regarded as significant. Chi-square test was used to evaluate the strength of association between Doppler findings and IVF outcome with $\mathrm{P}<0.05$ taken as statistically significant.

\section{RESULTS}

A total of 107 patients were included in this study. There was no significant difference in age, BMI, cause and duration of infertility, number of retrieved oocytes, number of embryos transferred and serological hormone levels on day 3 and on the day of HCG administration between the three study groups $(\mathrm{P}>0.05)$. Their mean age was 33 years. The mean endometrial thickness was $7.1 \mathrm{~mm}$ in Group A, $8.4 \mathrm{~mm}$ in Group B and $8.9 \mathrm{~mm}$ in Group C. The cause of infertility was tubal in 48 cases, anovulation in 37 and male factor in 22 cases. The endometrial blood flow was in zone I in 15 cases (Group A), Zone 2 in 36 cases (Group B) and Zone 3 in 56 cases (Group C). The pregnancy outcome was directly correlated with subendometrial-endometrial vascularity. The clinical pregnancy rate was highest in cases with zone 3 vascularity as compared to zone 2 and I (42.85\% vs. $27.77 \%$ and $6.66 \%$ ). 


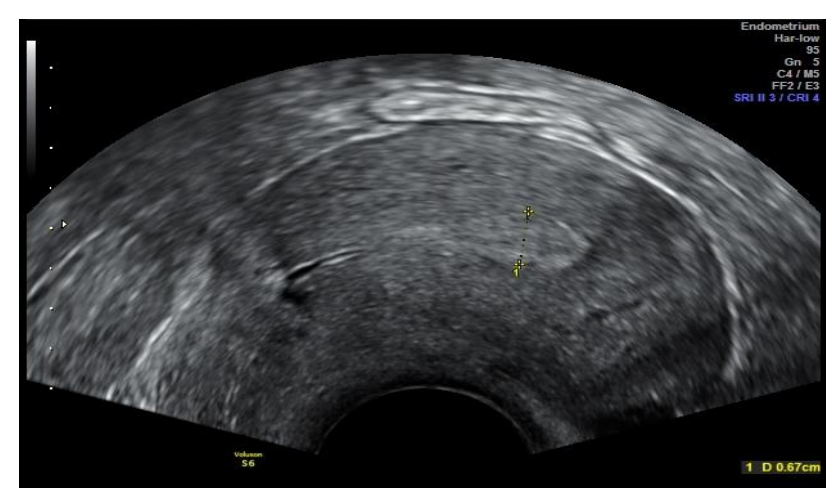

Figure 1: Endometrial thickness.

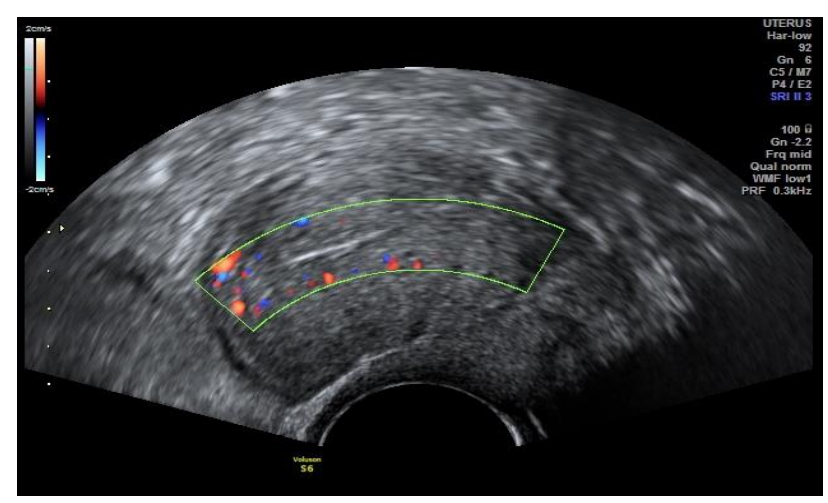

Figure 2: Endometrial zone I - Colour doppler study.

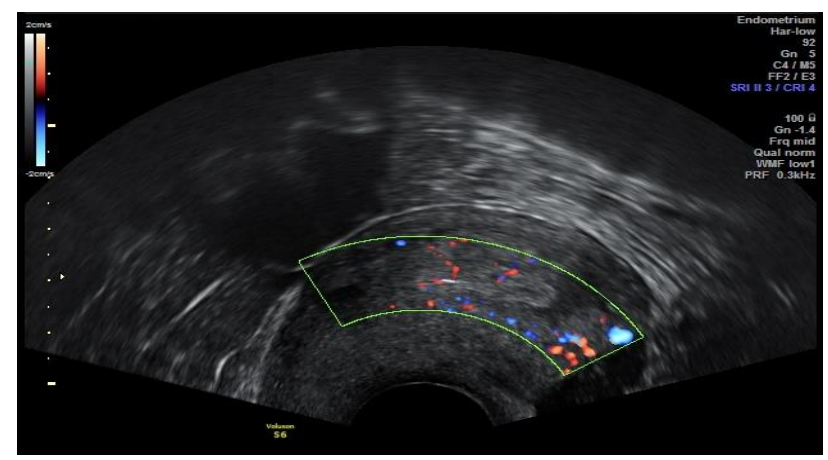

Figure 3: Endometrial zone II - Colour doppler study.

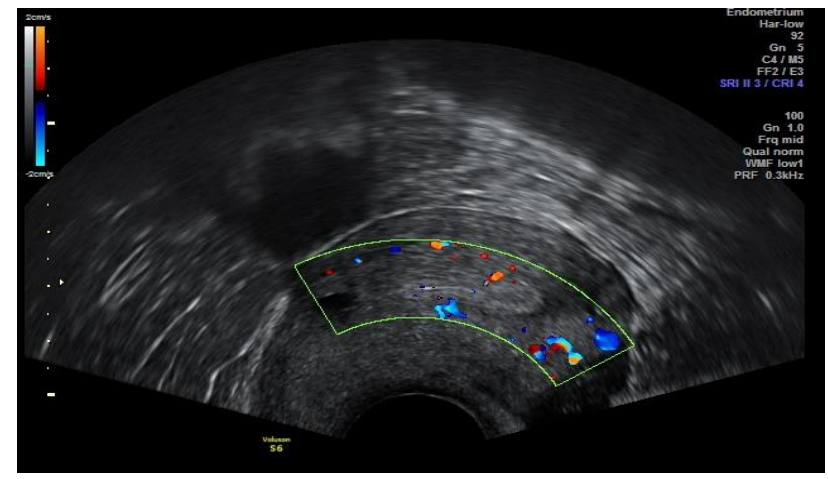

Figure 4: Endometrial zone III - Colour Doppler study.
Similarly, the implantation rate was also highest in cases with zone 3 vascularity ( $23.20 \%$ vs. $11.22 \%$ and $2.38 \%)$. Simultaneously the rate of biochemical pregnancy and miscarriage rate was lowest in cases with zone 3 vascularity $(20.83 \%$ Vs $40 \%$ and $100 \%)$. There was one twin pregnancy in Group B and five twin pregnancies in Group C.

Table 1: Distribution according to cause of infertility.

\begin{tabular}{|ll|l|}
\hline Causes of Infertility & Numbers & $\%$ \\
\hline Tubal Factor & 48 & $44.86 \%$ \\
\hline Anovulation & 37 & $34.58 \%$ \\
\hline
\end{tabular}

Table 2: Distribution according to Zone of vascularity.

\begin{tabular}{|ll|l|}
\hline Zone of Vascularity & Numbers & $\%$ \\
\hline Zone I (Gr. A) & 15 & $14.02 \%$ \\
\hline Zone 2 (Gr.B) & 36 & $33.64 \%$ \\
\hline Zone 3 (Gr. C) & 56 & $52.34 \%$ \\
\hline
\end{tabular}

Table 3: The relationship between subendometrialendometrial blood flow and IVF-ET/ICSI outcomes.

\begin{tabular}{|llll|}
\hline Parameters & Gr A & Gr B & Gr C \\
\hline No. of Cases & $15 / 107$ & $36 / 107$ & $56 / 107$ \\
\hline $\begin{array}{l}\text { Pregnancy Rate } \\
(\beta-H C G \geq 50)\end{array}$ & $\begin{array}{l}2 / 15 \\
(13.33 \%)\end{array}$ & $\begin{array}{l}12 / 36 \\
(33.33 \%)\end{array}$ & $\begin{array}{l}(45 / 56 \\
(44.64 \%)\end{array}$ \\
\hline $\begin{array}{l}\text { Clinical } \\
\begin{array}{l}\text { Pregnancy Rate } \\
(\text { CPR })\end{array}\end{array}$ & $\begin{array}{l}1 / 15 \\
(6.66 \%)\end{array}$ & $\begin{array}{l}10 / 36 \\
(27.77 \%)\end{array}$ & $\begin{array}{l}24 / 56 \\
(42.85 \%)\end{array}$ \\
\hline $\begin{array}{l}\text { Implantation Rate } \\
(\text { IR) }\end{array}$ & $1 / 42$ & $11 / 98$ & $29 / 125$ \\
& $(2.38 \%)$ & $(11.22 \%)$ & $(23.20 \%)$ \\
\hline $\begin{array}{l}\text { Multiple } \\
\text { pregnancy Rate }\end{array}$ & - & $1-$ Twin & $5-$ Twin \\
\hline $\begin{array}{l}\text { Poor pregnancy } \\
\text { Outcome (PPO) }\end{array}$ & $\begin{array}{l}2 / 2 \\
(100 \%)\end{array}$ & $4 / 10(40 \%)$ & $5 / 24(20.83 \%)$ \\
\hline
\end{tabular}

Table 3: $P$ value.

\begin{tabular}{|lll|}
\hline & Group A Vs. C & Group B Vs. C \\
\hline CPR & 0.036 & 0.113 \\
\hline IR & 0.005 & 0.032 \\
\hline PPO & 0.876 & 0.465 \\
\hline
\end{tabular}

\section{DISCUSSION}

The assessment of the endometrial receptivity is the key for success of all ART procedures. The advantages of Ultrasonography include its non-invasiveness, repeatability, real-time monitoring and predictability, however Ultrasonographic findings indicating changed endometrial receptivity have not yet been acknowledged. The different Sonographic markers of receptivity are endometrial thickness, pattern, echogenicity and Colour Doppler study of uterine and endometrial blood flow. ${ }^{7-10}$ The vascular changes are reflection of the biochemical changes and can be studied by the Power and color 
Doppler. Colour Doppler energy imaging is a technology based on the total integral of energy frequency spectrum. It visualizes blood flow with the energy of moving reflectors and enjoys the advantages of high sensitivity to slow blood flow while being less dependent on angles and providing a less cluttered image.

While uterine artery PI and RI indices are commonly being used, they are not reflective of endometrial blood flow. The pulse Doppler values give objective while colour mapping give subjective assessment of the endometrial vascularity although the colour areas can also be quantified. ${ }^{11} 3 \mathrm{D}$ Power Doppler ${ }^{12-15}$ assess the global vascularity as compared to $2 \mathrm{D}$ ultrasound Doppler ${ }^{9,11,16,17}$ 3D Ultrasound allows studying not only the endometrial volume but also the quantitative assessment of vessel density and blood flow within the endometrium and sub-endometrial region. 3D USG has a very low inter-observer and intra-observer variability for calculating endometrial volume.

While some authors have found that vascular resistance in the subendometrial endometrial arteries was significantly lower on the day of oocyte retrieval or embryo transfer in patients who achieve pregnancy ${ }^{10,13}$ others have found no differences. ${ }^{7-9,14}$

Recently it has been proposed that the day of HCG administration is the best day to evaluate the uterine receptivity. ${ }^{15,18}$ This is based on the reports of increased impedance of uterine arteries after HCG Injection and its influence on the predictive value of Ultrasonography. ${ }^{19}$ So, we selected the day of HCG for 3D-Power Doppler assessment in our study.

The absence of colour mapping of the endometrium and subendometrial areas means an absolute implantation failure $^{9,20}$ or a significant decrease ${ }^{17}$ of the implantation rate. This resembles with our study as the implantation rate was $2.38 \%$ in group $\mathrm{A}$ as compared to group $\mathrm{C}$ $23.20 \%$ (p 0.005) and $11.22 \%$ in group B as compared to group C $23.20 \%$ (p-0.032).

Conversely, the pregnancy rate, increases when the vessels reach the subendometrial halo and endometrium. ${ }^{9,17}$ In our study the clinical pregnancy rate was highest in group C $(42.85 \%)$ with vascularity up to zone 3 in comparison to group A (6.66\%) with vascularity only up to zone 1 (p-0.036).

The presence of vessels within the endometrium is associated with a thicker endometrium. ${ }^{17}$ The mean endometrial thickness was $7.1 \mathrm{~mm}$ in group $\mathrm{A}$ as compared to $8.9 \mathrm{~mm}$ in group $\mathrm{C}$, suggests a correlation between endometrial perfusion and growth.

When pregnancy is achieved but endometrialsubendometrial flow on the day of ET cannot be seen, more than half of these pregnancies will end in spontaneous miscarriage. ${ }^{17}$ This suggests that the development of the endometrial vascular network is important for the support of the first stages of pregnancy. In our study, poor pregnancy outcome was high in group A as compared to group C (100\% vs. $20.83 \%$, p 0.876$)$. The absence of statistical significance was due to gross difference in sample size of two groups.

In our study, we also found an increased multiple pregnancy rate in those who have better endometrial blood flow (one in group B Vs. five in group C) but the case number is too small to draw any conclusion.

\section{CONCLUSION}

Assessment of endometrial receptivity by 3D-Power Doppler study of subendometrial-endometrial blood flow is a simple, non-invasive method especially if the primary ultrasound markers of endometrial receptivity are poor (ET $<7.0 \mathrm{~mm}$, hyperechoic or presence of subendometrial calcification). We can also reduce the number of transferred embryos in cases of good vascularity and this can reduce the rate of multiple pregnancy and its complications.

Embryo freezing until endometrial blood flow is good enough for ET is another option to improve IVF outcome. Though still larger studies are needed to establish more precise ultrasound values / parameters to understand the endometrial physiological status better and achieve better pregnancy rates with ART procedures.

\section{Funding: No funding sources \\ Conflict of interest: None declared \\ Ethical approval: Not required}

\section{REFERENCES}

1. Edwards RG. Clinical approaches to increasing uterine receptivity during human implantation. Hum Reprod. 1995;10:60:6.

2. Noyes RW, Hertig AT, Rock J. Dating the endometrial biopsy. Fertil Steril 1950;1:3-25.

3. Lédéé-Bataille N, Lapréé-Delage G, Taupin JL, Dubanchet S, Frydman R, Chaovat G. Concentration of Leukaemia inhibitory factor (LIF) in uterine flushing fluid is highly predictive of embryo implantation. Hum Repord.2002;17:213-18.

4. Blumenfold Z, Dirnfeld M, Beck H. Comparison of treatment of uterine Leiomyomata with three GnRH agonistic analogues-efficacy and side effects. In vickery B and lunenfield B (Eds) GnRH analogues in cancer and Human Reproduction. 1990; 3:45.

5. Goldberg BB, Liu JB, Kuhlman K, Merton DA, Kurtz AB. Endoluminal gynaecologic ultrasound: Preliminary results. J ultrasound Med. 1991;10:58390.

6. Fanchin R. Assessing uterine receptivity in 2001; Ultrasonographic glances at the new Millennium. An NY Acad Sci. 2001;943:185-202. 
7. Schild RL, Knobloch C, Dorn C, Fimmers R, Vander Ven H, Hansmann M. Endometrial receptivity in an in-vitro fertilization program as assessed by spiral artery blood flow, endometrial thickness, endometrial volume, and uterine artery blood flow. Fertil Steril 2001;75:361-66.

8. Yuval Y, Liptz S, Dor J, Achiron R. The relationship between endometrial thickness and blood flow and pregnancy rate in in-vitro fertilization. Human Repord.1999;14:1967-71.

9. Zaidi J, Campbell S, Pittrof R, Tan SL. Endometrial thickness, morphology, vascular penetration and velocimetry in predicting implantation in in-vitro fertilization Programme. Ultrasound Obstet Gynecol. 1995;6:191-8.

10. Battaglia C, Artini PG, Giulini S, Salvatori M, Maxia N, Petraglia F et al . Colour Doppler changes and thromboxane production after ovarian stimulation with GnRH agonist. Hum Repord;1997; 11:2477-82.

11. Yang JH, Wu MY, Chen CD, Jiang MC, Ho HN, Yang YS. Association of endometrial blood flow as determined by a modified Colour Doppler technique with subsequent outcome of in-vitro fertilization. Hum Repord.1999;14;1606-10.

12. Jarvela IY, Sladkevicims P, Kelly S, Ojha K, Campbell S, Nargund G. Evaluation of endometrial receptivity during in-vitro fertilization using threedimensional Power Doppler ultrasound. Ultrasound Obstet Gynecol. 2005;26:765-9.

13. Kupesic S, Bekavac I, Bjelos D, Kurjak A. Assessment of endometrial receptivity by Transvaginal colour Doppler and three dimensional Power Doppler Ultrasonography in patients undergoing in-vitro fertilization procedures. J Ultrasound Med.2001;20:125-34.

14. Ng EH, Chan CC, Tang OS, Yeung WS, Ho PC. The role of endometrial and subendometrial blood flows measured by three-dimensional Power Doppler Ultrasound in the prediction of pregnancy during IVF treatment. Hum Reprod.2006; 21:164170.

15. Wu HM, Chiang CH, Huang HY, Chao AS, Wang HS, Soong YK. Detection of the subendometrial vascularisation flow index by three-dimensional ultrasound may be useful for predicating the pregnancy rate for patients undergoing in-vitro fertilization-embryo transfer. Fertil Steril.2003;79:507-11.

16. Applebaum M. The uterine biophysical profile ultrasound. Obstet Gynecol.1995; 5:67-8.

17. Chien LW, Au HK, Chew PL, Xiao J. Assessment of uterine receptivity by the endometrialsubendometrial blood flow distribution pattern in women undergoing in-vitro fertilization-embryo transfer. Fertil-Steril. 2002;78:245-51.

18. Dechaud H, Bessueille E, Bosquet PJ, et al. Optimal timing of Ultrasonographic and Doppler evaluation of uterine receptivity to implantation. Repord. Biomed online 2008;16(3):368-75.

19. Merce LT, Barco MJ, Bau S. et al. Are endometrial parameters by three-dimensional ultrasound and power Doppler angiography related to in-vitro fertilization/embryo transfer outcome? Fertil Steril 2008;89(1):111-17.

20. Bassil S. Changes in endometrial thickness, width, length and pattern in predicting pregnancy outcome during ovarian stimulation in in-vitro fertilization. Ultrasound Obstet Gynecol.2001; 18:258-63.

21. Wang L, Qiao J, Li R. et al. Role of endometrial blood flow assessment with colour Doppler energy in predicting pregnancy outcome- Reprod. Biol Endocrinol 2010; 18(8):122.

Cite this article as: Choudhary M, Chowdhary $\mathrm{J}$, Swarankar ML, Bharadwaj SL. Predictive value of subendometrial - endometrial blood flow assessment by transvaginal 3D power doppler on the day of HCG on clinical outcome of IVF cycles. Int J Res Med Sci 2015;3:3114-8. 